\title{
A SEPULTURA SOB TUMULUS DO SENHOR DOS AFLITOS (ALVARENGA/ AROUCA, CENTRO-NORTE DE PORTUGAL). PRIMEIROS RESULTADOS
}

\author{
GABRIEL ROCHA PEREIRA ${ }^{(1)}$
}

Resumo:

Publicam-se os resultados dos trabalhos de escavação, realizados no âmbito da arqueologia empresarial, no monumento sob tumulus do Senhor dos Aflitos, freguesia de Alvarenga, concelho de Arouca, Noroeste de Portugal, entre Fevereiro e Julho de 2008. A publicação destes resultados torna-se particularmente importante quer por se tratar de um monumento sob tumulus inédito quer devido às suas especificidades arquitetónicas. $\mathrm{O}$ monumento do Senhor dos Aflitos é provido de um montículo artificial de dimensões médias, no centro do qual se encontrava uma cista "megalítica". Apesar de não existirem evidências de restos ósseos, foram encontradas fragmentos de vários recipientes cerâmicos que indiciam oferendas funerárias.

As características construtivas do monumento e do espólio recolhido na área central levam-nos a colocar a hipótese de que este teria sido construído provavelmente durante o Bronze Inicial Não se excluem, no entanto, reutilizações em fases posteriores da Idade do Bronze.

Palavras-chave: Idade do Bronze, contextos e práticas funerárias, monumento sob tumulus, cista "megalítica", oferendas cerâmicas.

\begin{abstract}
:
The grave under tumulus of Senhor dos Aflitos (Alvarenga / Arouca, central north of Portugal). First results. The present article discusses the results of the archaeological digging of a pre-historic tomb surveyed in February and July of 2008. This monumental site is located in a parish of Alvarenga, municipality of Arouca, Nothwest of Portugal. The publication of these results becomes particularly important either because it is an unpublished monument either due to their architectural characteristics. The monument of the Senhor dos Aflitos is provided with an artificial mound of medium size, in the center of which was found a 'megalithic' cist. Although no evidence of skeletal remains, fragments of ceramic vessels indicate burial offerings.
\end{abstract}

Key-words: Bronze Age, burial contexts and practices, tumulus and "megalithic"cist; ceramic offerings.

Received: 2 December 2013; Accepted: 21 March, 2014

\section{INTRODUÇÃO}

O monumento sob tumulus do Senhor dos Aflitos foi descoberto no âmbito de prospeções arqueológicas realizadas pelo Centro de Arqueologia de Arouca, tendo sido inventariada na Carta Arqueológica de Arouca com o número 020. Posteriormente, foi descrito como sendo um tumulus de médias dimensões, com cerca de 10 metros de diâmetro e entre 0,50 e 1 metro de altura (SILVA 2004:171).

Em 2005 a apresentação à Câmara Municipal de Arouca de um pedido de licenciamento de construção para o local próximo do monumento, levou a Autarquia a solicitar pareceres ao Centro de Arqueologia de Arouca e ao Instituto Português de Arqueologia, tendo estas instituições proposto uma pequena intervenção arqueológica essencialmente de reconhecimento do arqueossítio, uma vez que o projeto de construção não previa a afetação direta do monumento. Todavia, em Dezembro de 2006, em resultado de trabalhos de florestação que não foram devidamente acompanhados por arqueólogos, o montículo tumular foi seriamente danificado, parecendo que apenas a área central teria ficado preservada, o que levou o IPA a determinar que a execução do projeto em licenciamento deveria ser precedida da escavação integral do que restasse da sepultura, por forma a recuperar alguma informação científica possível. O terreno ficaria, posteriormente, liberto para as finalidades desejadas.

No quadro destas ocorrências, e com base em caderno de encargos facultado ao promotor pelo Centro de Arqueologia de Arouca, a intervenção veio a ser adjudicada à entidade empresarial $\mathrm{J}$. Menéndez, Lda. Arqueologia e Serviços, tendo sido realizada entre 30 de Janeiro e 15 de Fevereiro de 2008, sob direção do signatário.

Após os trabalhos o relatório de escavação foi entregue e aprovado pela tutela e foram apresentados os resultados no evento Arqueologia D' Entre Paiva e Arda 2008 - Trabalhos e Descobertas Recentes, realizado em 07 de Junho de 2008, do qual não foram publicadas actas. Deste modo, os resultados da escavação permaneceram inéditos. Atendendo às características arquitetónicas do monumento, ao espólio recolhido

(1) Mestre em Arqueologia. Investigador do Centro de Investigação Transdisciplinar "Cultura, Espaço e Memória" - CITCEM/UP. Centro de Arqueologia de Arouca. pereira.gr@gmail.com. 
e ao facto de se conhecer muito pouco sobre este tipo de contextos funerários no Centro-Norte Litoral, consideramos a sua publicação pertinente e importante para o conhecimento da Idade do Bronze desta área mais litoral.

\section{ENQUADRAMENTO FÍSICO E ARQUEOLÓGICO}

O monumento localiza-se no distrito de Aveiro, concelho de Arouca, freguesia de Alvarenga, no lugar do Senhor dos Aflitos. O acesso é relativamente fácil, podendo fazer-se pela estrada municipal n. ${ }^{\circ}$ 326-1, cortando-se em direção à Capela do Senhor dos Aflitos, situada no topo da colina. As coordenadas geográficas em graus, minutos e segundos, no sistema WGS84, são as seguintes: Latitude: $40^{\circ} 57^{\prime} 29^{\prime \prime} \mathrm{N}$ e Longitude: $08^{\circ} 09^{\prime} 50^{\prime \prime}$ W. A altitude do local situa-se entre os $440 \mathrm{~m}$ e os $450 \mathrm{~m}$ (Fig.1).
O monumento foi implantado numa reduzida plataforma, no alto da vertente noroeste do Monte do Senhor dos Aflitos, sobranceiro ao vale de Alvarenga e ao rio Paiva, que corre 250 metros mais abaixo na vertente sudoeste.

$\mathrm{O}$ enquadramento geológico imediato do sítio, assim como o terreno de fundação do monumento, são dados pelo afloramento de uma rocha ígnea plutónica, de natureza granitóide, com grão médio e contendo moscovite e biotite (granito de duas micas), não porfiroide (MEDEIROS et al. 1964; SÁ et al. 2008:31-32). Pela observação direta é possível afirmar que existem na área de diversas ocorrências de quartzo leitoso.

Em um raio inferior a $3 \mathrm{Km}$ para $\mathrm{N}$ e $\mathrm{W}$ existem recursos mineiros de volframite (MEDEIROS et al. 1964:54), sendo de realçar que o próprio topo do Monte do Senhor dos Aflitos foi objeto de uma concessão mineira datada de 1913.

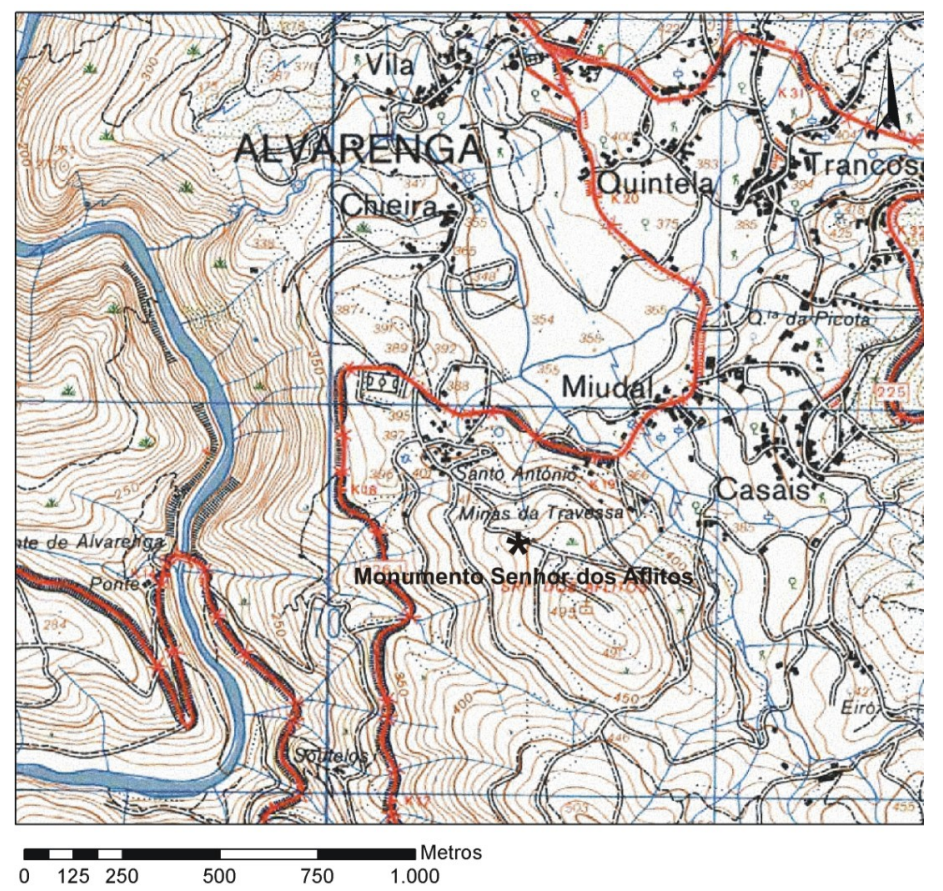

Fig. 1. Localização do Monumento do Senhor dos Aflitos, Excerto da Carta Militar de Portugal, 1:25000.

Fig. 1. Location of the Monument of Senhor dos Aflitos, in the "Carta Militar de Portugal", 1:25000.

A área revela um contexto arqueológico interessante (Fig. 2). O carácter simbólico do local em época pré-histórica revela-se pela presença do possível menir do Senhor dos Aflitos, se bem que talvez deslocalizado, implantado numa pequena plataforma da encosta sudeste do monte, em posição visualmente dominante sobre todo o sector sul e este do vale de Alvarenga (PEREIRA DA SILVA \& SILVA 1994; SILVA 2004:172).
Paralelamente, no topo da colina do Senhor dos Aflitos, além da pequena capela, está localizado o Castro de Alvarenga, sítio caracterizado como povoado do Bronze Final (SILVA 1994:47-8; SILVA 2004:248), datação que o espólio resultante de uma pequena sondagem arqueológica entretanto efetuada, aparentemente veio confirmar. ${ }^{1}$ Nas proximidades de monumento regista-se, ainda, numa rocha algumas covinhas, que se encontram por levantar e estudar.

Agradecemos a António Manuel Silva e a Paulo Lemos a oportunidade de consultar o relatório resultante das escavações efetuadas neste povoado, entregue e aprovado pela tutela. 


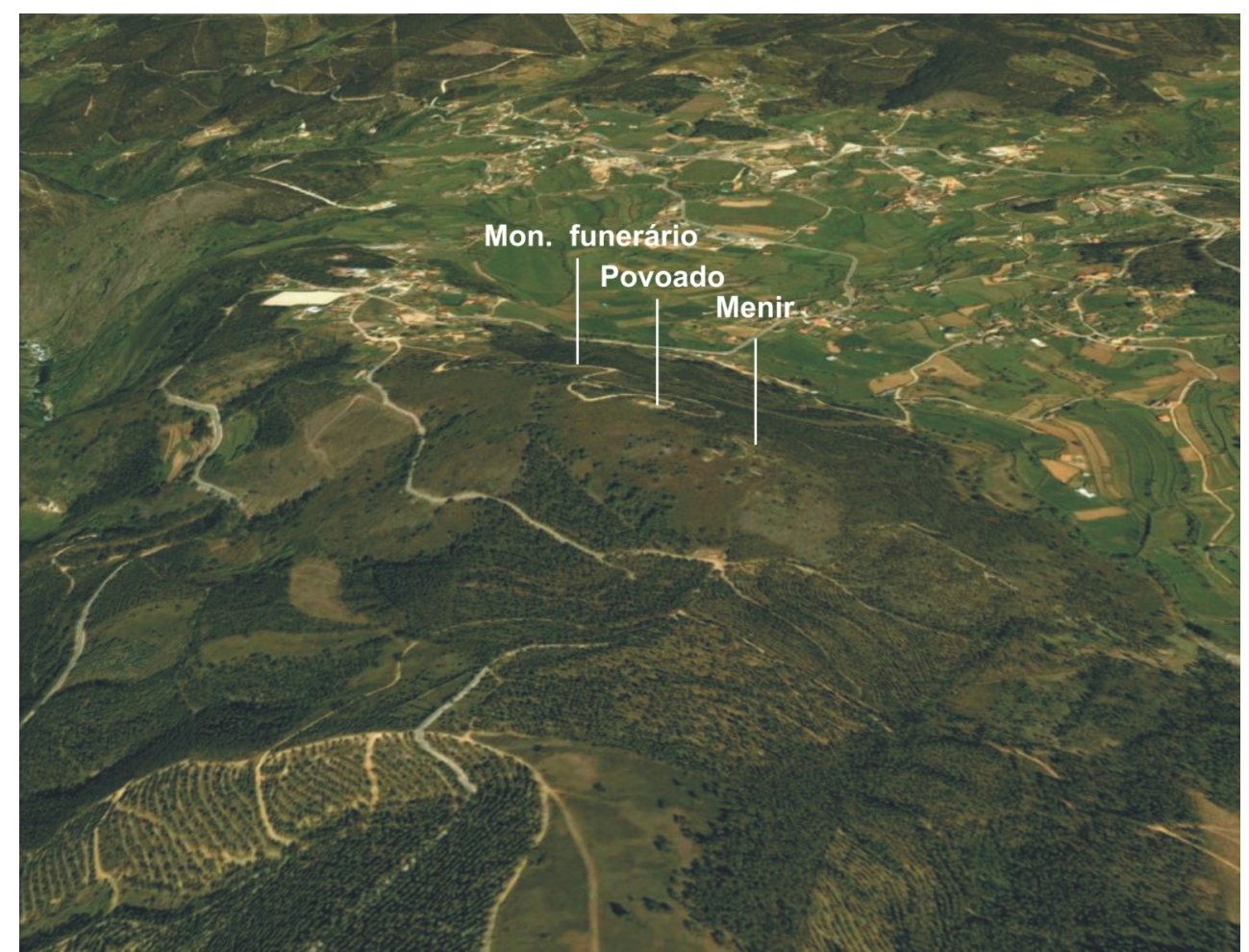

Fig. 2. Sítios arqueológicos no Monte do Senhor dos Aflitos (Google Earth ${ }^{\circledR}$ ).

Fig. 2. Archaeological sites in the "Monte Senhor dos Aflitos" (Google Earth $®)$.

\section{METODOLOGIA}

Com base no caderno de encargos e nas condições técnicas contratuais, os trabalhos arqueológicos visaram avaliar o estado de conservação deste imóvel, caracterizá-lo em termos construtivos, bem como, naturalmente, identificar e registar eventuais restos de práticas e de ritos funerários preservados.

Assim, numa primeira fase procedeu-se à limpeza superficial da vegetação e remoção dos

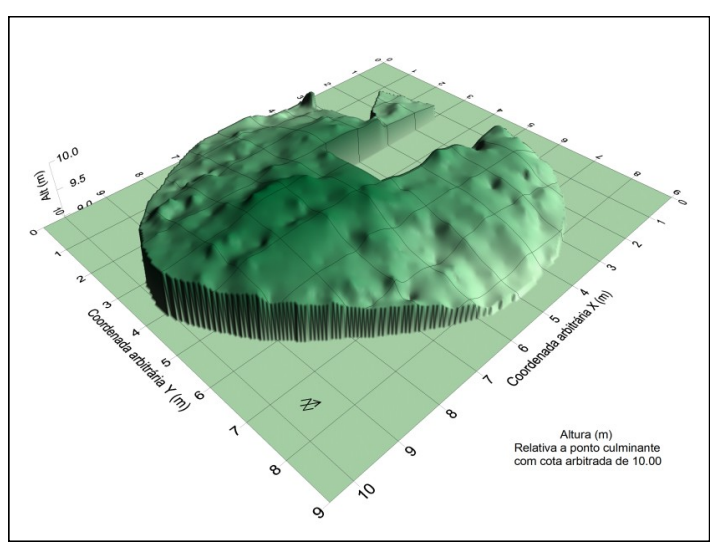

Fig. 3. Levantamento topográfico do monumento (a área a branco corresponde à escavação arqueológica). Aplicação do programa informático Surfer 6.0.

Fig. 3. Topographic survey of the tomb (the white area corresponds with the archaeological dig). Software application Surfer 6.0 . aterros provocados pelos trabalhos de florestação. Esta tarefa tinha como objetivo delimitar fisicamente os seus limites, por forma a que fosse possível proceder ao respetivo levantamento topográfico (Figs. 3 e 4). A segunda fase correspondeu à avaliação do estado de conservação do monumento e ao conhecimento das suas características construtivas, através da realização de uma sondagem arqueológica. Esta foi implantada uma sondagem alinhada segundo a disposição cardeal nordeste-sudoeste, com 7 metros de comprimento por 2 metros de largura, a fim de tentar caracterizar a arquitetura do monumento e o respetivo montículo artificial.

A seleção da área a intervencionar, localizada na zona de maior impacto provocado pela florestação, obedeceu essencialmente a um critério de preservação do monumento, uma vez que, não obstante as recomendações da entidade de tutela, o proprietário do terreno havia optado, entretanto, pela conservação daquele elemento arqueológico.

A metodologia de escavação e registo utilizada seguiu os pressupostos de Edward Harris (HARRIS 1979), posteriormente sistematizado por outros autores, como Andrea Carandini (CARANDINI 1983).

Após a escavação o monumento foi tapado com geotêxtil, areia, terra e pedra. De forma a repor a sua morfologia original, garantindo-se a sua preservação. 


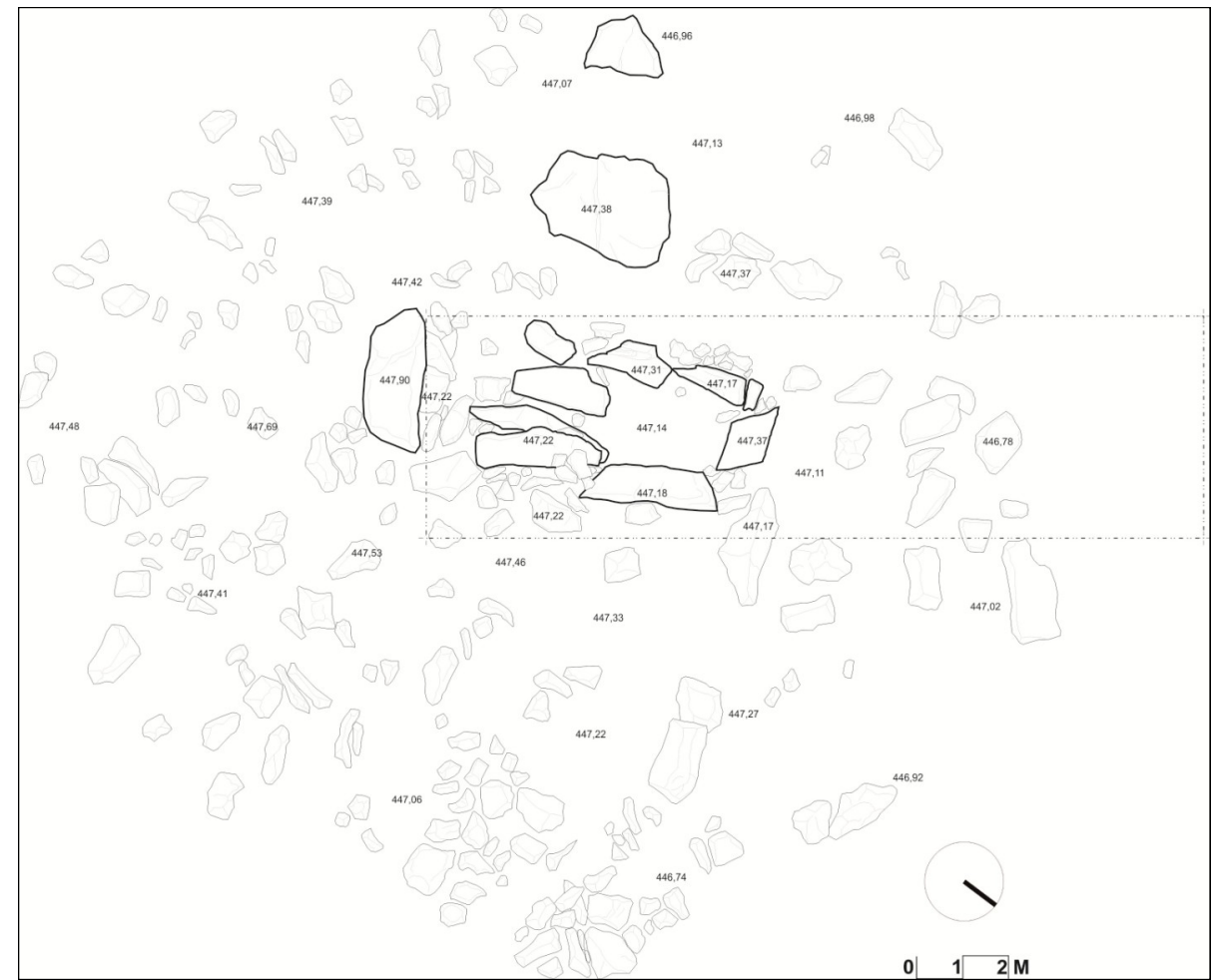

Fig. 4. Levantamento topográfico do monumento (a área a cinzento corresponde à escavação arqueológica). Fig. 4. Topographic survey of the tomb (the grey area corresponds with the archaeological dig).

\section{ESCAVAÇÃO}

Após a limpeza superficial da área verificou-se que, não obstante as assinaláveis perturbações no tumulus, decorrentes das ações de florestação referidas, a estrutura arquitetónica central parecia apresentar-se em relativo bom estado de preservação, o que a escavação subsequente viria a confirmar.

Nos trabalhos de escavação identificaramse 28 unidades estratigráficas (UE), incluindo as estruturas arqueológicas e os sedimentos que se acumularam sobre o tumulus, bem como as ações destrutivas a que este foi objeto ao longo da sua temporalidade (Fig. 5).

Assim, ao contrário do que inicialmente se supunha, observou-se uma estrutura tumular ainda relativamente bem preservada, de dimensões e complexidades significativas. Embora, a câmara funerária se apresentasse violada, foi possível reconstituí-la com alguma verosimilhança a planta do monumento, assim como a estruturação do tumulus.

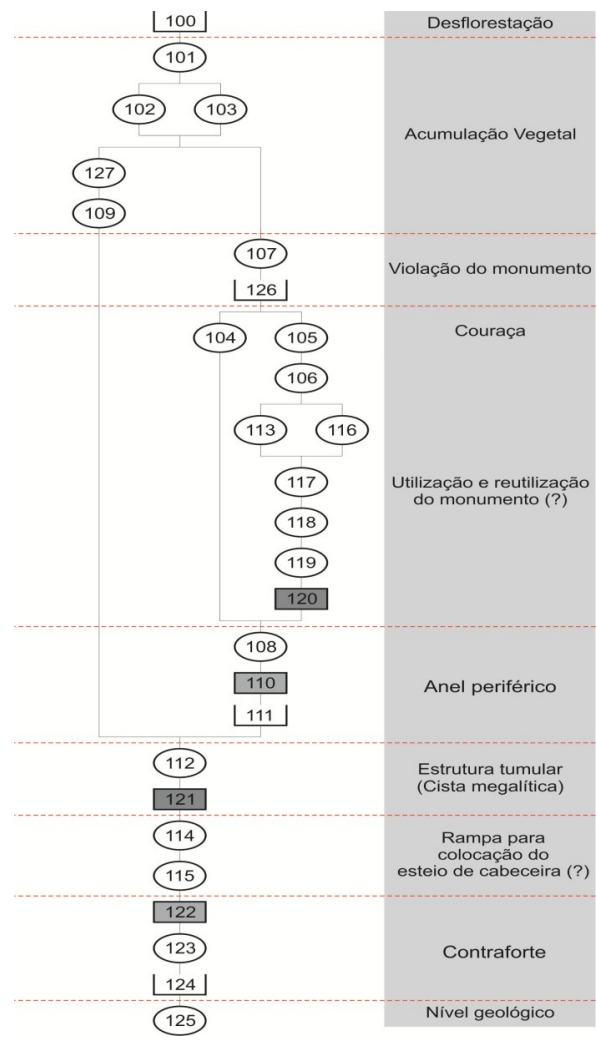

Fig. 5. Matriz estratigráfica.

Fig. 5. Harris matrix. 


\subsection{Estratigrafia e características arquitetónicas}

Após a limpeza superficial do monumento e do registo do respetivo interface horizontal [100], relacionado com os trabalhos de florestação, detetaram-se algumas unidades estratigráficas associadas a processos pós-deposicionais, compostas por depósitos vegetais que sucessivamente cobriram o monumento. O primeiro [101], com aproximadamente 0,10 metros de espessura, corresponde ao nível vegetal atual, que cobria um segundo depósito [102 e 103], de menor espessura com cerca de 0,08 metros. O último processo pós-deposicional [109 e 127], identificado nos limites externos do monumento, em zona de declive, apresentou uma espessura variável, tendo em determinados pontos ultrapassado os 0,20 metros (Fig. 6). Este episódio sedimentar, de coloração escura, quase negra, poderá estar associado à acumulação sucessiva de materiais contra o monumento, funcionando como elemento de contenção de terras.

Deste modo, importa notar que a atual "invisibilidade" do monumento reveste-se de um carácter aparente, fruto dos sucessivos níveis vegetais que paulatinamente se acumularam sobre ele, chegando a atingir cerca de 0,50 metros de altura, especialmente no sentido oeste-este, ou seja a favor da pendente do terreno original.

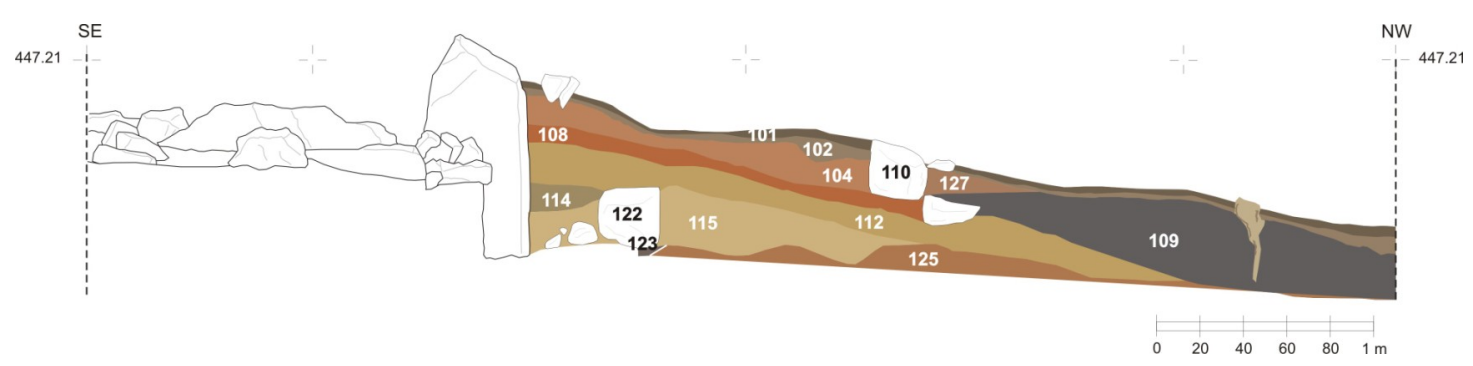

Fig. 6. Perfil estratigráfico SE-NW do monumento.

Fig. 6. Stratigraphic profile SE-NW of the tomb.

\subsubsection{O tumulus}

A escavação permitiu caracterizar a estrutura do tumulus. Este corresponde, genericamente, a um montículo formado pela acumulação de sedimentos que, ora assentam sobre um anel lítico, existente em torno da câmara (contraforte), ora assentam sobre o substrato geológico, nas zonas mais periféricas, onde foram contidos por um anel lítico localizado na periferia do monumento.

A primeira fase de construção deste monumento parece ter correspondido à abertura de uma pequena vala no afloramento rochoso [124], com cerca de $0,70 \mathrm{~m}$ de largura por de $0,15 \mathrm{~m}$ de profundidade e de base aplanada que rodeava a câmara funerária, pelo menos, pelo lado $\mathrm{NW}$, onde abrimos a sondagem, sendo nítido, no entanto que se prolongava para ambos os lados da mesma. A base do esteio $\mathrm{n} .{ }^{\circ} 1$, de cabeceira, assentava no seu interior. O seu enchimento era composto, no fundo, por um depósito com evidentes sinais de combustão [123], podendo tratar-se, talvez, de indícios de uma queimada. No sentido de se poder obter uma referenciação cronológica absoluta foi guardada uma amostra deste depósito para análises radiométricas que não foram realizadas por falta de meios, dado estarmos perante uma escavação realizada no quadro da arqueologia empresarial. O interior da vala, sobre o depósito anterior, foi colmatado com blocos de quartzo leitoso, dispostos sensivelmente na horizontal, com exceção da área próxima do esteio n. ${ }^{\circ} 1$ onde estes estavam fincados de forma oblíqua, servindo de cunhas [122]. Este contraforte era composto maioritariamente por blocos angulosos em quartzo leitoso e tinha cerca de 0,90 metros de largura (Figs. 7 e 8).

As terras do tumulus não eram uniformes, pois este foi construído através da deposição de sucessivas camadas de sedimentos argilosos, bem compactados, que apresentavam uma disposição diagonal, rampeada, e se iam recobrindo do interior para o exterior [115 e 112]. A primeira cobria o contraforte e caracterizava-se por um conjunto de sedimentos de coloração castanho amarelado, argilo-arenosa, homogénea, de grão médio a grosseiro, com pedras de pequeno a médio calibre (quartzo, xisto, quartzito e granito), compactos [115]. Sendo a segunda [112], de coloração castanho avermelhado, argilo-arenosa, homogénea, igualmente compacta, de grão médio, com pedras de pequeno calibre (quartzos) e raízes. Na periferia deste depósito e sobre ele, foi construído um anel lítico de contenção externa que delimita a totalidade do monumento [110] formando uma área sub-elíptica, com um eixo maior de aproximadamente 7,50 metros, no sentido ESE-WNW, e com um eixo menor de cerca de 6 metros, no sentido oposto. De salientar que este anel estava parcialmente destruído pelos trabalhos de desflorestação pelo que as suas dimensões são aproximadas. Este era constituído por um círculo de monólitos de maiores dimensões, em quartzo leitoso e granito, intercalados entre si, fincados de forma vertical ou oblíqua para o interior, num ângulo de aproximadamente $45^{\circ}$. 


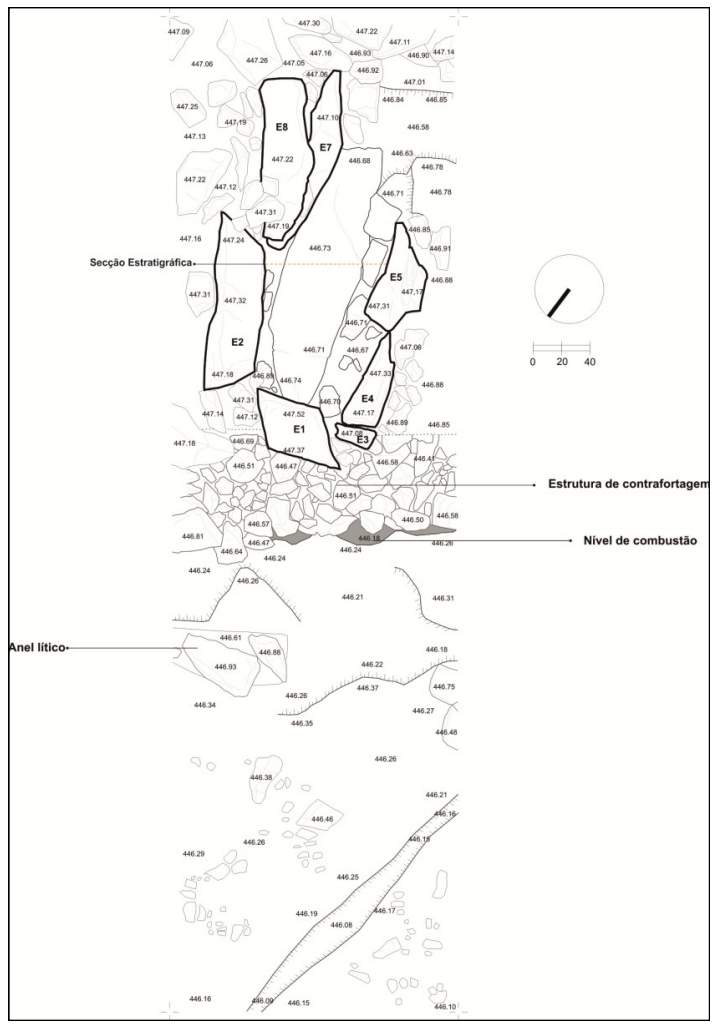

Fig. 7. Pormenor do monumento após a escavação arqueológica. Identificação das estruturas mencionadas no texto.

Fig. 7. Detail of the monument after the archaeological dig. Identification of the structures mentioned in the text.

O último depósito argiloso [108] ficava imediatamente sob a couraça lítica, composta por blocos de tamanho diverso, essencialmente de granito, quartzo leitoso e xisto [UE 104]. Esta encontrava-se bastante perturbada pelos trabalhos de florestação que aqui ocorreram (Fig. 9).

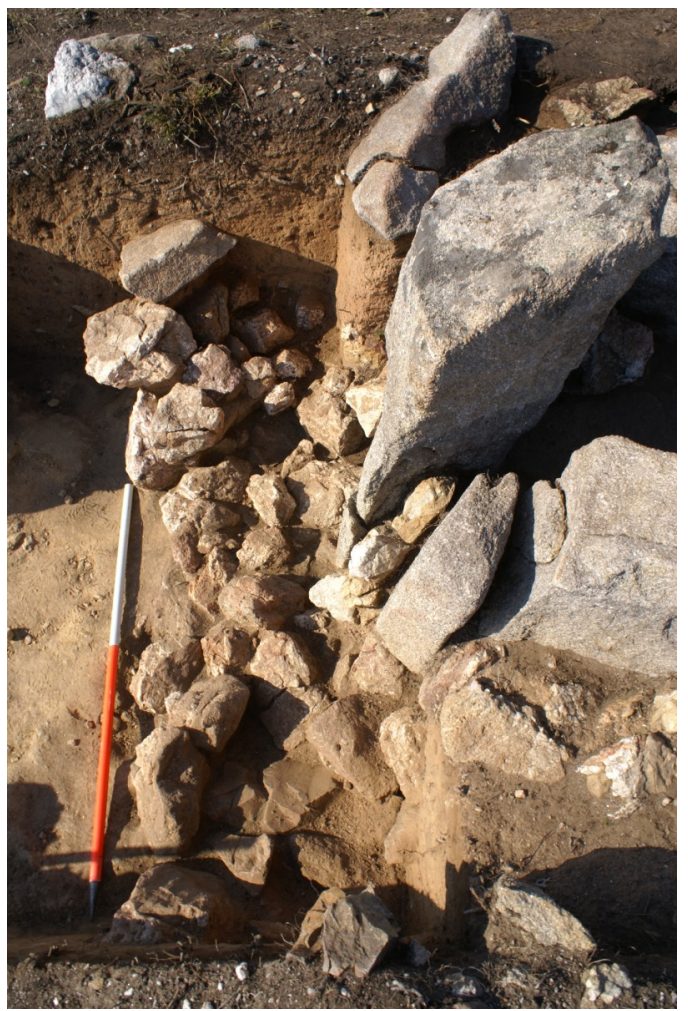

Fig. 8. Pormenor do anel lítico de contrafortagem.

Fig. 8. Detail of the counterfort ring of the funerary chamber.

De salientar, ainda, que sobre o contraforte, foi depositada uma unidade estratigráfica peculiar, não só pelo facto de se encontrar circunscrita espacialmente sobre a estrutura de contrafortagem, mas também no que concerne à sua composição, tendo-se aí recolhido algumas amostras de minerais, entre os quais limonite de coloração castanho-amarelado.

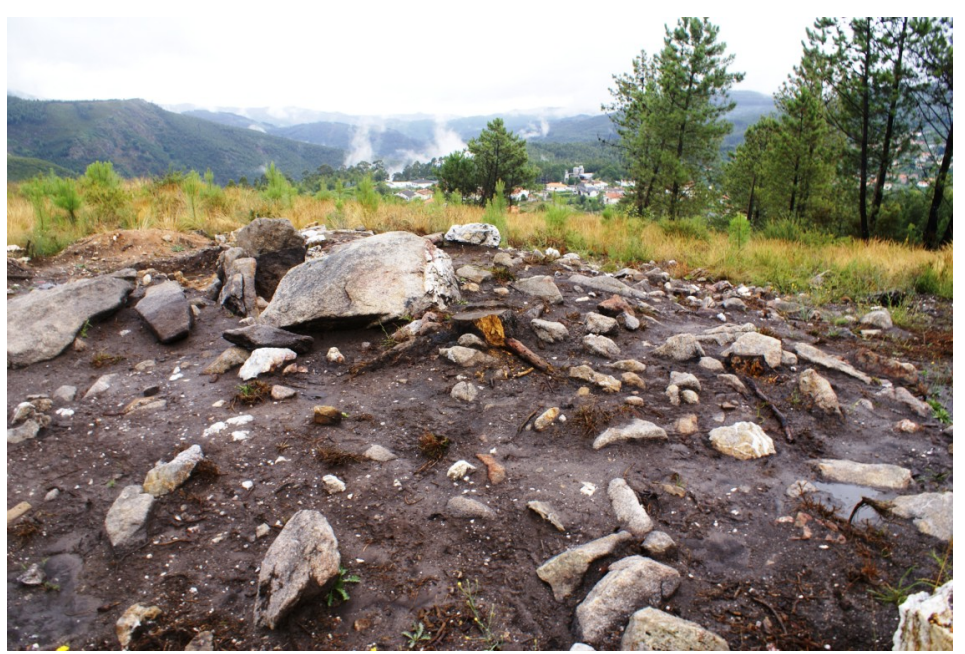

Fig. 9. Perspetiva geral da couraça lítica, vista de Sul; sendo visível (à esquerda) algumas lajes que poderiam ter correspondido às tampas da cista funerária.

Fig. 9. General perspective of the mound, view of South, being visible (at the left) what it could be part of the slab that covered the funerary cist. 


\subsection{2. Área central}

$\mathrm{Na}$ área central do monumento, após a remoção do manto vegetal [103], foram identificadas oito unidades estratigráficas (Fig. 10). As mais recentes relacionam-se com a violação do monumento, de cronologia incerta, e respetivo depósito de acumulação [107 e 126]. Estas estendiam-se pelo quadrante sudeste do tumulus. O saque consistiu na remoção da laje de cobertura, a qual perturbou a disposição original de alguns dos esteios, bem como alguns dos depósitos associados à utilização do espaço de enterramento [105, 106, 113 e $116]$.

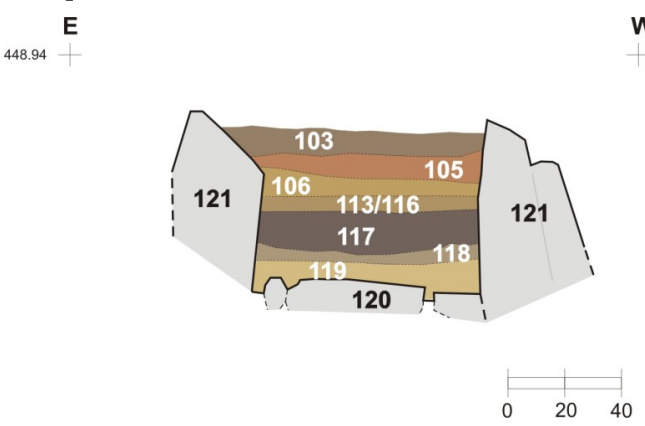

Fig. 10. Secção estratigráfica do interior da câmara.

Fig. 10. Stratigraphic cross-section of the interior of the chamber.

As restantes unidades estratigráficas [117, 118 e 119], referentes à utilização do espaço sepulcral, de espessuras francamente diminutas, cobriam uma laje em granito [120] que constituía a base da câmara. Tinha 0,50 metros de largura por 1,93 metros de comprimento e cerca de 0,20 metros de espessura. Este monólito, orientado $240^{\circ} \mathrm{N}$, apresenta um contorno entre o antropomórfico e fálico e encontrava-se ladeado por blocos de quartzo leitoso de médio porte e ainda por umas pequenas lajes em granito (Fig. 11). Considerando a necessi-

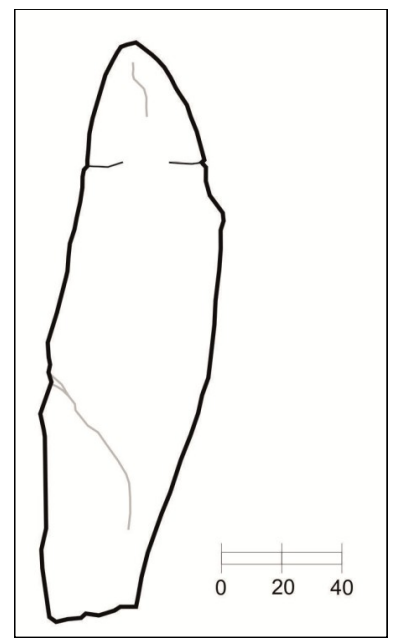

Fig. 11. Representação da eventual "estela-menir" Fig. 11. Representation of the possible "Estela-menhir" dade de preservar o monumento, não foi possível efetuar o seu levantamento; não obstante, o aprofundamento da escavação numa área imediatamente contígua, a noroeste, permitiu observar a espessura do monólito, que parece rondar os $0,20 \mathrm{~m}$.

Embora a câmara do monumento [121] tenha sido violada, dela preservaram-se cinco esteios in situ, todos eles calçados por pedras de pequenas e médias dimensões, um esteio deslocado e no, mínimo, um esteio fragmentado e tombado. A sua construção ter-se-á iniciado com a colocação do esteio de cabeceira na vertical, dentro do valado e sobre o contraforte [122]. O esteio de cabeceira parece ter-se fracturado aquando da sua colocação original, pelo que terá sido colocado, como uma espécie de reforço estrutural, um esteio de menores dimensões, que denominámos de esteio n. ${ }^{\circ}$ 3. A câmara seria, provavelmente, de planta sub-retangular, orientada segundo o seu eixo maior na direção ESE-WNW, sendo composta por oito esteios (Fig. 12). Com exceção do esteio de cabeceira e do n. ${ }^{\circ} 6$, os restantes estavam dispostos na horizontal, e forravam as paredes laterais da cista. $\mathrm{O}$ esteio n. ${ }^{\circ} 6$ encontrava-se semi-inclinado para o interior do espaço sepulcral, num ângulo de $45^{\circ}$, o que nos leva a supor que estaria disposto na vertical e faria o fecho da câmara, sensivelmente pelo lado este. Apenas um esteio estava deslocado, o n. ${ }^{\circ} 8$, que estava depositado sobre o esteio n. ${ }^{\circ} 7$.

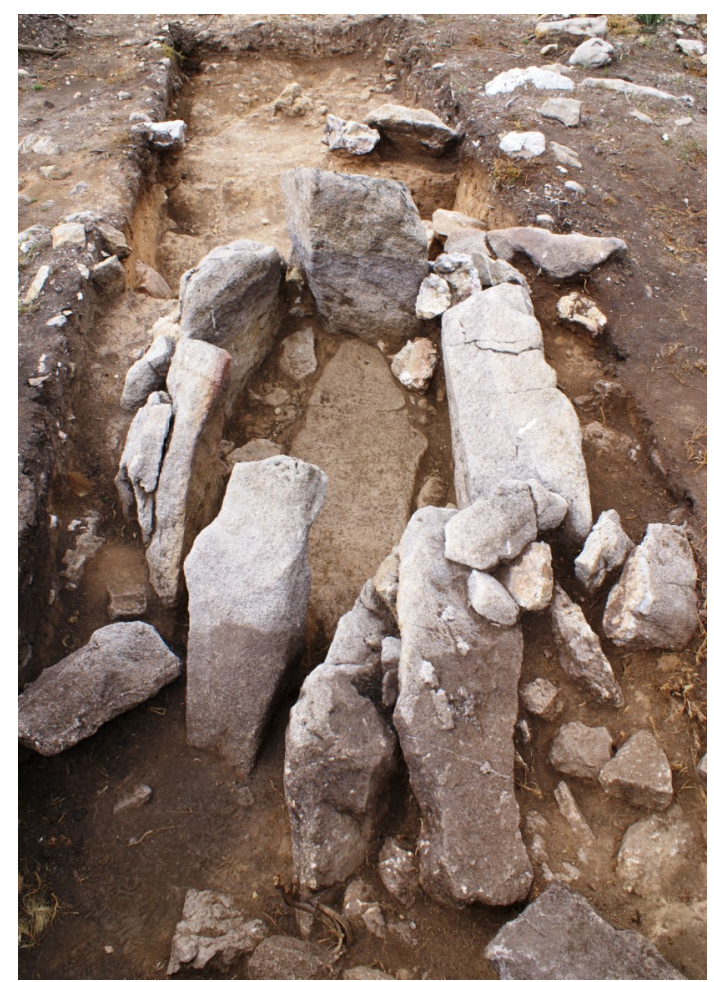

Fig. 12. Pormenor da área da câmara.

Fig. 12. Detail of the funerary chamber. 
A altura dos esteios era variada, embora só tivesse sido possível medir o esteio de cabeceira na totalidade, pois foi o único que se escavou até aos alicerces. Assim, apesar da sua altura máxima ser de 1,20 metros, em relação à base do túmulo tinha apenas 0,78 metros de altura, sendo, portanto, apenas ligeiramente mais alto do que os restantes que variavam entre os 0,60 e os 0,74 metros de altura. Não contabilizámos o esteio $\mathrm{n}^{\circ} 3$ por ter sido considerado um reforço do n. ${ }^{\circ} 1$. A largura variava entre os 0,37 metros do n. $^{\circ} 6$ (o mais estreito), e os 1,18 metros do esteio lateral n. ${ }^{\circ} 7$. A espessura, com exceção do esteio de cabeceira, com $0,60 \mathrm{~m}$, e do seu reforço, o esteio $\mathrm{n}^{\circ}$ 3, era bastante uniforme, ou seja, entre os 0,20 os 0,40 metros (Tabela 1).

Tabela 1. Dimensões dos esteios que compõem a cista Table 1. Orthostats of the cist dimensions

\begin{tabular}{|c|c|c|c|}
\hline Esteios & \multicolumn{3}{|c|}{ Dimensões (m) } \\
\hline Designação & Altura & Largura & Espessura \\
\hline E1 & 1,20 (total) & 0,46 & 0,60 \\
\hline E2 & 0,74 (parcial) & 0,98 & 0,40 \\
\hline E3 & 0,38 (parcial) & 0,20 & 0,10 \\
\hline E4 & 0,68 (parcial) & 0,72 & 0,26 \\
\hline E5 & 0,61 (parcial) & 0,58 & 0,30 \\
\hline E6 & 0,74 (parcial) & 0,37 & 0,24 \\
\hline E7 & 0,60 (parcial) & 1,18 & 0,26 \\
\hline E8 & 1,11 (total) & 0,36 & 0,10 \\
\hline
\end{tabular}

Trata-se, pois de uma cista de tradição megalítica, de grandes dimensões, com 2,30 metros de comprimento máxima por 1,00 metro de largura máxima, formada por três esteios de cada lado e um em cada extremidade. A sua altura seria relativamente baixa, na ordem dos 0,70 metros, pelo que é de supor que a laje de cabeceira ficasse um pouco sobrelevada, o que poderia servir de elemento de contenção em relação às lajes de cobertura. Embora se apresentasse desprovida de cobertura, pensamos que alguns fragmentos de lajes existentes sobre o montículo artificial, poderiam fazer parte desta, tendo em conta as suas dimensões $(1,18 \mathrm{~m} \times 0,80 \mathrm{~m})$.

As lajes apresentam superfícies alisadas na sua face interna e tonalidades ora ferruginosas ora amareladas, podendo caracterizar-se do ponto de vista litológico, na sua maioria, por apresentarem uma matriz granular de cor acinzentada, razoavelmente homogénea, não orientada, onde se distinguem facilmente com lupa de pequena ampliação grãos milimétricos sensivelmente equigranulares de dois tipos de feldspato, de quartzo, todos muito abundantes, e ainda de moscovite e, sempre, biotite subordinada. Para além destas características gerais, as lajes graníticas evidenciam ocasionalmente outras fenomenologias, nomeadamente fracturas com preenchimento ferruginoso (FF), superfícies de falha com estrias quartzosas distintas (FE) e veios planares milimétricos de quartzo (Vqz). A laje de base, apesar de ter naturalmente uma forma ligeiramente antropomórfica ou fálica, foi sujeita a alguma forma de afeiçoamento na sua face, havendo determinadas fraturas obtidas por percussão fina e outras por algum polimento/raspagem grosseira ${ }^{2}$.

\subsection{Deposições de artefactos}

Os materiais arqueológicos recolhidos correspondem, grosso modo, a fragmentos cerâmicos e a uma pequena quantidade de artefactos líticos (Tabela 2 e 3 ), o que poderá ser atribuído às perturbações descritas anteriormente.

Tabela 2. Distribuição dos materiais arqueológicos recolhidos na área da câmara

Table 2. Distribution of archaeological materials collected in the area of the chamber

\begin{tabular}{|l|c|c|}
\hline Unidade Estratigráfica & $\begin{array}{l}\text { Fragmentos } \\
\text { Cerâmicos }\end{array}$ & Líticos \\
\hline 105 - terras da cista perturbadas & 9 & - \\
\hline 106 - terras da cista perturbadas & 6 & - \\
\hline 113 - terras da cista perturbadas & 1 & - \\
\hline $\begin{array}{l}117 \text { - utilização do espaço } \\
\text { sepulcral? }\end{array}$ & 10 & - \\
\hline $\begin{array}{l}118 \text { - utilização do espaço } \\
\text { sepulcral? }\end{array}$ & 2 & - \\
\hline \begin{tabular}{l} 
Total \\
\hline
\end{tabular} & $\mathbf{2 8}$ & $\mathbf{0}$ \\
\hline
\end{tabular}

Tabela 3. Distribuição dos materiais arqueológicos recolhidos à superfície ou no tumulus

Table 3. Distribution of archaeological materials collected at the surface or in the sediments of the tumulus

\begin{tabular}{|l|c|c|}
\hline Unidade Estratigráfica & $\begin{array}{c}\text { Fragmentos } \\
\text { Cerâmicos }\end{array}$ & Líticos \\
\hline Recolha de superfície & 3 & - \\
\hline 104 - couraça lítica & - & 4 \\
\hline 112 - terras do tumulus & & 1 \\
\hline 115 - terras do tumulus & & 1 \\
\hline Total & $\mathbf{3}$ & $\mathbf{6}$ \\
\hline
\end{tabular}

Classificação e análise do geólogo Manuel João Abrunhosa, a quem muito agradecemos. 


\subsubsection{Cerâmicas}

O espólio recolhido procede maioritariamente da área central do monumento e corresponde a trinta e um fragmentos cerâmicos, de fabrico manual, pastas com desengordurantes que incluem pequenos fragmentos de quartzo e alguma mica, com cozeduras redutoras que serão responsáveis pelas superfícies com tonalidades que variam entre o cinzento e o castanho e cernes geralmente escuros. Os acabamentos são essencialmente alisados. Surgiram dois fragmentos decorados que correspondem a um bordo e a um bojo com aplicações plásticas, nomeadamente, mamilos, com cerca de $1 \mathrm{~cm}$ de espessura e de contorno arredondado (Fig. 13).

Ao nível do reportório formal além do bordo aberto, decorado com um mamilo, de paredes tendencialmente oblíquas, que parece articulável com um fragmento de fundo plano, dadas as suas características técnicas e morfológicas, correspondendo assim a um vaso troncocónico. Merece nota ainda o aparecimento de um pequeno fragmento de uma taça carenada, um fragmento de asa e de um pequeno bordo e bojo de uma forma de paredes retas ou subcilíndricas. Não obstante a posição superficial destes fragmentos [105 e 106], consideramos que devem ser contextualizados no âmbito da construção e utilização da sepultura, devendo-se o seu enquadramento estratigráfico à violação do espaço funerário.

Os fragmentos cerâmicos mais indubitavelmente associados à fase de utilização do monumento [117 e 118], são mais incaracterísticos do ponto de vista formal, correspondendo maioritariamente a fragmentos de bojo de reduzidas dimensões, de superfícies lisas e com vestígios de polimento.

Finalmente, nas terras superficiais do monumento foram recolhidos três outros fragmentos cerâmicos de bojos de recipientes, resultantes das alterações provocadas pela maquinaria aquando dos trabalhos de florestação.

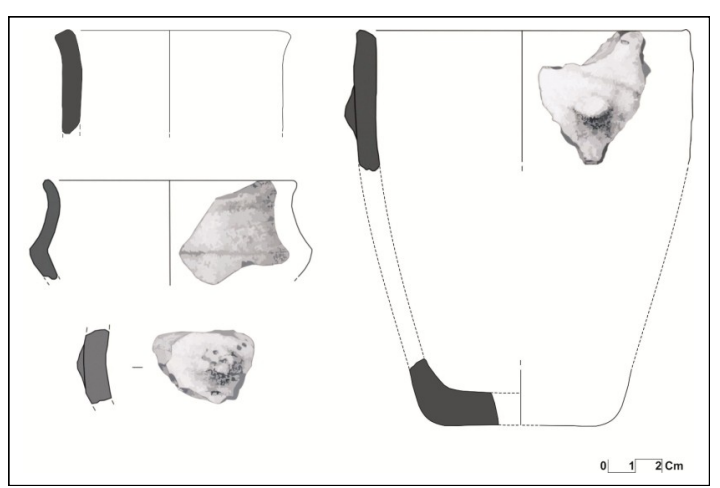

Fig. 13. Cerâmica encontrada no interior do monumento.

Fig. 13. Pottery found inside the tomb.

\subsubsection{Líticos}

O material lítico exumado provém essencialmente da área do tumulus, integrando a couraça lítica do monumento, tendo-se recolhido dois fragmentos de dormentes de moinhos manuais, um presumível movente, em granito, e um presumível amolador em xisto (Fig. 14), assim como dois cristais de quartzo.

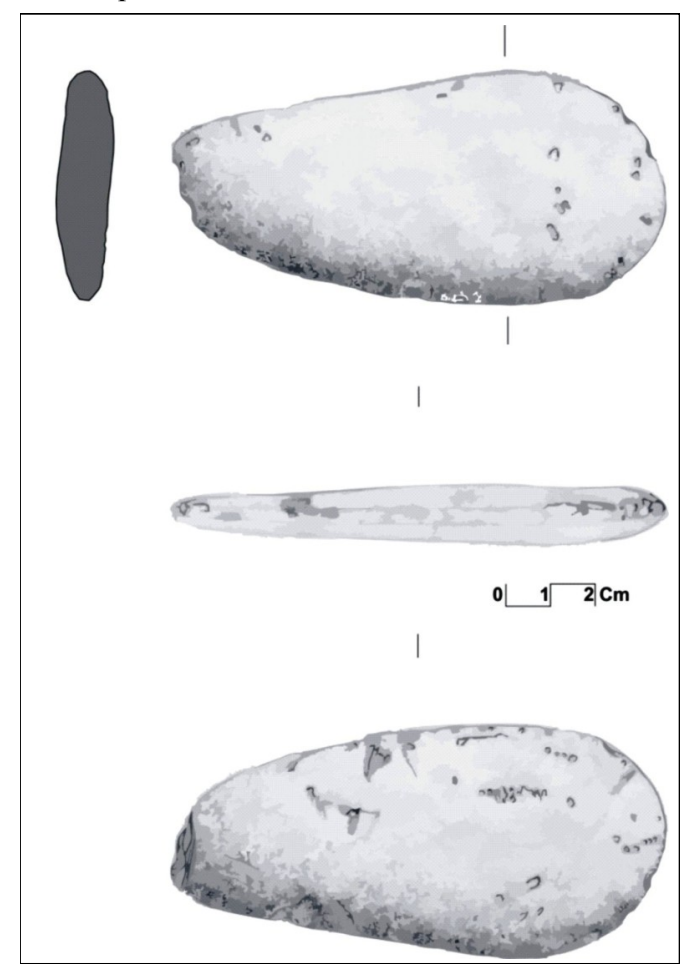

Fig. 14. Material lítico recolhido no tumulus (possível amolador).

Fig. 14. Stone object found in the mound of the monument. (possible whetstone).

\section{DISCUSSÃO DOS RESULTADOS E CONSIDERAÇÕES FINAIS}

Apesar dos níveis de afetação a que foi sujeito ao longo do tempo, os resultados obtidos durante os trabalhos de escavação permitiram caracterizar o monumento do Senhor dos Aflitos como uma estrutura funerária sob tumuli de pequenas dimensões, de contorno atualmente sub-elíptico, com cerca de 1 a 1,5 metro de altura, com câmara em cista de tradição megalítica.

Do ponto de vista estrutural, destaca-se um tumulus provido de contraforte, acumulação de sedimentos, couraça lítica superficial e anel lítico periférico que serviu para conter a couraça, para além de outras funções simbólicas de mais difícil escrutínio, considerando nomeadamente a presença de volumosos blocos de quartzo leitoso que não deixariam de acentuar, a visibilidade do monumento.

Elemento que naturalmente há que destacar é a laje de base da câmara sepulcral, cuja morfologia 
entendemos ser assimilável a uma configuração fálica (com a coroa da glande marcada por pequenos sulcos simétricos) e com ligeiro contorno antropomórfico. Não tendo sido possível, pelas razões já indicadas, proceder ao levantamento desta peça, que assimilamos a uma "estela-menir", não deixamos de valorar a sua morfologia que cremos intencional e, portanto, portadora de um significado preciso no âmbito das práticas funerárias, talvez num quadro de uma ideologia que valoriza a fertilidade no momento da morte. De notar que desde o neolítico há pequenos seixos ou esteios afeiçoados, associadas a monumentos funerários (BUENO RAMÍREZ et al. 2008; GUARDAMINO URIBE 2009; CORREIA 2010).

Curiosa é, também, a seleção de elementos escolhidos para a construção deste monumento, desde a grande quantidade de quartzo leitoso, no interior do valado, no contraforte e na base da câmara ladeando a "estela-menir" (o que demonstra a sua importância, mesmo quando não é para ser visto), até à sua ocorrência de forma mais visível na couraça superfícial mas sobretudo no anel periférico. No monumento ainda ocorre o granito e o xisto, numa fusão dos três tipos de rochas e minerais existentes em termos locais, embora nem sempre das imediações do monumento, como é o caso do xisto. O mesmo se poderá considerar em relação aos fragmentos de limonite de coloração castanho-amarelado e que compunha os sedimentos [114] que cobriam o contraforte, cuja proveniência situar-se-á nas proximidades da povoação de Vilarinho, sita a cerca de $2 \mathrm{Km}$ a W do monumento, onde se assinala uma crosta limonítica, de origem supergénica (MEDEIROS et al. 1964:54). De sublinhar a seleção dos esteios para a construção da cista funerária, compostos especialmente por granitos de cores alaranjadas e avermelhadas.

Todas estas observações sugerem a intencional seleção de elementos naturais num quadro simbólico de práticas e ritos fúnebres onde as diferentes "matérias-primas" e cores eram significantes no momento da construção e utilização do monumento, o que indicia que as matérias construtivas não são escolhidas por motivos oportunistas mas por motivos culturais.

Quer em termos da sua volumetria quer dos seus elementos construtivos cremos que este monumento foi feito para ser visto e para perpetuar a recordação do cadáver enterrado.

No que respeita ao mobiliário funerário, os escassos cristais de quartzo provenientes das terras dos tumulus poderão ter sido trazidos acidentalmente. Já a presença de elementos de moinhos manuais, se bem que fraturados, na couraça pétrea, parecem ser intencionais e portadores de uma mensagem para os construtores deste monumento. De notar que são muito comuns desde o Neolítico embora ocorram em contextos tumulares da Idade do Bronze, como é o caso do túmulo 2 de Vale Ferreiro, Fafe (BETTENCOURT et al. 2005), na cista grande de Agro de Nogueira, Toques (MEIJIDE CAMESElle 1995), no monumento sob tumulus da Serra da Muna 1, Viseu (CRUZ et al. 1998a) que Bettencourt (2011) interpretou como sendo intencionais e fazendo parte de ritos de fertilidade ligados ao ciclo agrícola em associação com práticas funerárias.

Já no que se refere à cerâmica, não obstante ser escassa e se encontrar em parte descontextualizada, dada a violação parcial da câmara, permitirá algumas notas de maior interesse. Atendendo a alguma heterogeneidade de pastas, cores e acabamentos de superfície, é possível que os fragmentos cerâmicos recuperados possam corresponder à deposição de vários recipientes, no interior da câmara. No plano morfológico é de destacar, contudo, a existência de uma taça carenada, de um possível recipiente subcilíndrico e de, pelo menos, dois vasos decorados com aplicações plásticas mamilares, sendo um deles um troncocónico.

Esta última forma tem numerosos paralelos em diversos contextos funerários do Noroeste Peninsular, como sepulturas planas (necrópole de Cimalha, Felgueiras); cistas sem tumulus (necrópole de Chedeiro, Cualedro; cista de A Forxa, Riós; cista de Lordelo, Viana do Castelo, cista de Cabriadas/Gorgolão, Montalegre, entre outras) (BETTENCOURT 2009, 201133); monumentos sob tumuli de tradição megalítica, como o monumento da Serra da Muna 2, Viseu (CRUZ et al. 1998a) e reutilizações de monumentos megalíticos, exemplo Mamoa 1 de Madorras, Sabrosa (GonçAlves \& CRUZ 1994). Pelas datas de radiocarbono efetuadas para alguns contextos com este tipo de vasos as suas balizas cronológicas situam-se entre o Bronze Inicial e o Bronze Médio (BetTenCourt 1999, 2010), pelo que este monumento se situará entre estes dois momentos cronológico-culturais.

No entanto, as suas características construtivas e os paralelos existentes possibilitam mais algumas reflexões cronológicas. Apesar de, na Beira Alta, se terem descoberto, outros monumentos similares em termos arquitetónicos, como é o caso do Rapadouro 2 (CRUZ 2001) e do Pousadão 1 (CRUZ et al. 2000), dos vários monumentos estudados um dos que melhor se aproxima das características arquitetónicas do tumulus do Senhor dos Aflitos é a Mamoa 1 de Chã de Carvalhal, em Baião. Trata-se de um monumento sob tumulus de contorno circular, com cerca de 13 metros de diâmetro e de altura superior a 1 metro, com uma câmara retangular, constituída por seis esteios, medindo na direção oeste-este 1,50 metro por 1 metro de largu- 
ra (CRUZ 1992). Embora as datações radiométricas obtidas tenham sido anómalas, pelo espólio e pelas características construtivas arcaizantes, o autor, vinculado a tradições funerárias anteriores, considera que este monumento se terá construído na transição do Calcolítico para a Idade do Bronze (CRUZ 1992:115). Neste monumento apareceram pontas de seta de tipo Palmela e punhais de lingueta, em cobre. Recentemente, Bettencourt (2010) datou a cista da Quinta de Água Branca, em Vila Nova de Cerdeira, onde apareceu um punhal de lingueta similar aos encontrados na Chã do Carvalhal 1. A data obtita corresponde à transição do III para o II milénios a. C. o que coloca estes artefactos no Bronze Inicial. Assim sendo, é provável que o monumento sob tumulus do Senhor dos Aflitos possa ter sido erguido naquele período. De registar, ainda, o caso do tumulus de Outeiro de Gregos 1, em Baião, com câmara em cista de proporções consideráveis, datado também do Bronze Inicial (JORGE 1980, 1982; JORGE et al. 1988). dos finais do Bronze Médio/inícios do Bronze Final, apareceram duas taças carenadas de bordo reentrante. Esta forma é, no entanto, mais comum no Bronze Final, pelo menos no Noroeste português (BETTENCOURT 1999) e na Beira Interior (VILAÇA 1995). Tal característica permite pensar que este monumento possa ter sido reutilizado em período posterior à sua fundação, talvez entre os finais do Bronze Médio ou já no Bronze Final, reutilização que, talvez se possa articular com o povoado do Bronze Final existente no topo da colina do Senhor dos Aflitos (Silva 1994; SiLVA 2004).

Finalmente, ensaiámos ainda breve análise locacional do monumento, traçando - a partir do pressuposto de que a sua altura original rondaria $\mathrm{c}$. de 1 a 1,5 metros e tendo cientes os constrangimentos implícitos, no que compreende à falta de conhecimento do tipo de vegetação coeva - uma hipotética mancha de visibilidade (Fig. 15). O resultado obtido permite constatar que são principalmente os quadrantes NNE que possibilitam um

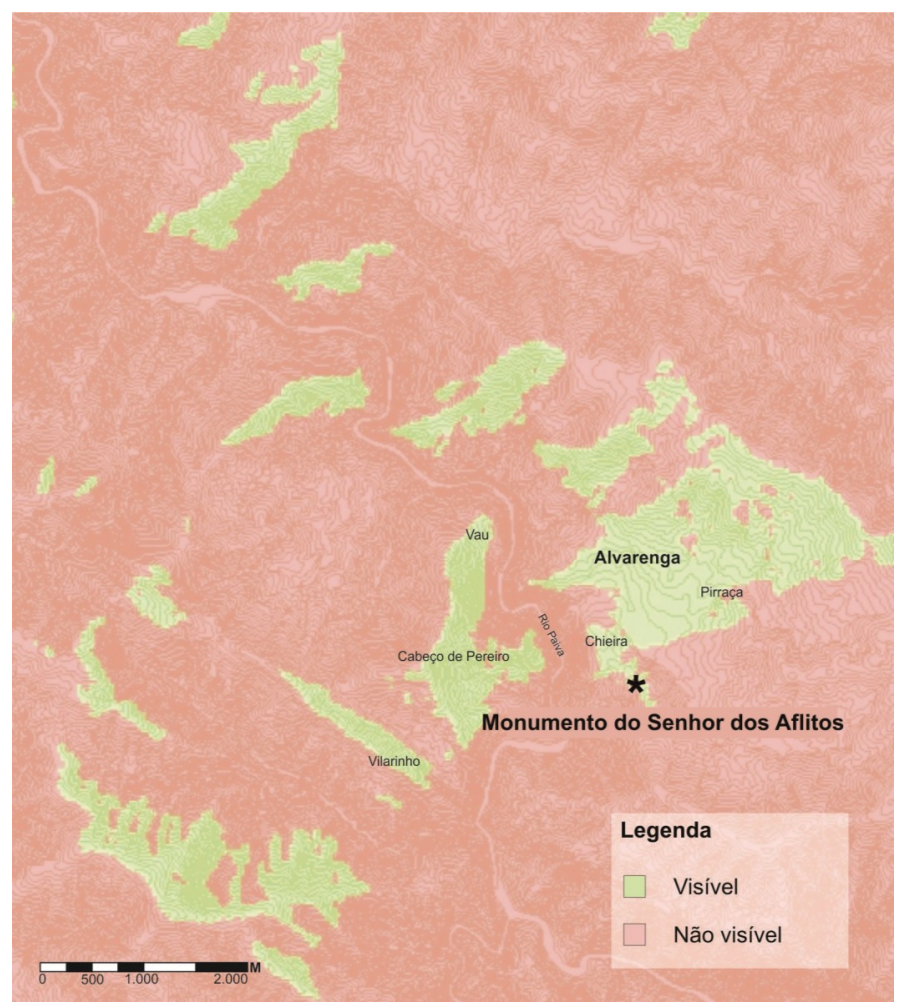

Fig. 15. Mapa de visibilidades do monumento em relação à paisagem envolvente. Fig. 15. Visibility map of the tomb to the surrounding area.

Falta ainda explicar a taça carenada de bordo esvasado aqui encontrada. Não sendo uma forma muito comum neste tipo de monumentos há notícia que terá aparecido uma em Monte Calvo 2, Arouca, na serra da Freita, num monumento de câmara em fossa, tapada com uma tampa megalítica, infelizmente impossível de datar radiometricamente (Pereira Da Silva 1997; Silva 2004:75; SÁ et al. 2014). Na Casinha Derribada 3, em Viseu, datado maior controlo visual de uma parte substancial do vale de Alvarenga e de alguns dos locais relacionados com a exploração de volframite (Vau, Cabeço de Pereiro, Chieira e Pirraça) e de limonite (Vilarinho) o que talvez se relacione com a área de vivência das populações que construíram este monumento. 


\section{BIBLIOGRAFIA}

BetTenCourT, A.M.S.1999. A Paisagem e o Homem na bacia do Cávado durante o II e o I milénios AC. 5 vols., Braga: Universidade do Minho (Tese de Doutoramento - Policopiada).

Bettencourt, A.M.S. 2009. Práticas Funerárias da Idade do Bronze de Trás-os-Montes e da Galiza Oriental, Actas do Congresso Transfronteiriço de Arqueologia. Outubro de 2008 [Revista Aqvae Flaviae, 41], $11-23$

Bettencourt, A.M.S. 2010. La Edad del Bronce en el Noroeste de la Península Ibérica: un análisis a partir de las prácticas funerárias. Trabajos de Prehistoria, 67 (1): 139-173.

BetTENCOURT, A.M.S. 2011. Estruturas e práticas funerárias do Bronze Inicial e Médio do Noroeste Peninsular. In P. Bueno, A. Gilman, C.M. Morales \& F.J.S. Palencia (eds.) Arqueologia, Sociedad, Territorio y Paisaje. Estudios sobre Prehistoria reciente, Protohistoria y Transición al mundo romano. [Bibliotheca Praehistorica Hispana, 28]. Madrid: Consejo Superior de Investigaciones Cientificas, 115-139.

BetTenCourt, A.M.S.; Rodrigues, A.; Silva, I.S.; CruZ, C.S. $\&$ DINIS, A. 2005. The ceremonial site of Vale Ferreiro, Fafe, in the context of the Bronze Age in Northwest Portugal. Journal of Iberian Archaeolog, 7:157-175.

Bueno RAmírez, P.; BAlbín Behrmann, R. \& BArroso BERMEJO, R. 2008. Dioses y antepasados que salen de las piedras. PH67 Especial Monografico - Boletín del Instituto Andaluz del Patrimonio Histórico, Consejería de Cultura - Junta de Andalucía, 47-61.

CARANDInI, A. 1983. Storie della terra. Manualle dello scavo archeologico. Bari.

Castro, A.S.; Silva, A.J.M.; Silva, C.R. \& Sebastian, L.C. 1997. Trabalhos de escavação arqueológica realizados no monumento 2 de Lameira Travessa (Pendilhe, Vila Nova de Paiva, Viseu). Estudos Pré -históricos, 3: 29-53.

CORREIA, A.M.V. 2010. Estelas e estátuas-menires no Centro e Norte de Portugal e Sudoeste da Meseta Superior. Coimbra: Faculdade de Letras da Universidade de Coimbra (Dissertação de Mestrado-Policopiada).

CRUZ, D.J. 1992. A mamoa 1 de Chã de Carvalhal no contexto arqueológico da serra da Aboboreira. Coimbra: Universidade de Coimbra.

CruZ, D.J. 2001. O Alto Paiva. Megalitismo, diversidade tumular e práticas rituais durante a Pré-história recente. Coimbra: Universidade de Coimbra (Dissertação de Doutoramento-Policopiada).

Cruz, D.J., Gomes, L.F.G. \& Carvalho, P.M.S. 1998a Monumento 2 da Serra da Muna (Campo, Viseu). Resultados preliminares dos trabalhos de escavação. Actas do colóquio: A Pré-história na Beira Interior (Tondela, Nov. 1997). [Estudos Pré-históricos 6]: 375-395.

CruZ, D.J., Gomes, L.F.G. \& CARVAlho, P.M.S. 1998b. O grupo de tumuli da Casinha Derribada (Concelho de Viseu). Conímbriga, 37: 5-76.

Gonçalves, A.H.H.B. \& CRUZ, D.J. 1994. Resultados dos trabalhos de escavação da Mamoa 1 de Madorras (S. Lourenço de Ribapinhão, Sabrosa, Vila Real). Estudos Pré-históricos, 2: 171-231.
GUARDAMINO URIBE, M.M.D. 2009. Las Estelas decoradas en la Prehistoria de la Península Ibérica. Madrid: Departamento de Prehistoria Facultad de Geografia e Historia, Universidad Complutense (Tese de doutoramento-Policopiada).

HARRIS, E.C. 1979. Principles of Archaeological Stratigraphy. London.

JoRGE, V.O. 1980. Escavação da Mamoa 1 de Outeiro de Gregos. Serra da Aboboreira, Baião. Portugália, 1 (Nova série): 9-28

Jorge, V.O. 1982. Megalitismo do Norte de Portugal: distrito do Porto. Os monumentos e a sua problemática no contexto europeu. Porto: Universidade do Porto (Tese de Doutoramento - Policopiada).

JORGE, V.O. 1985. Novas datações de radiocaborno para Mamoas do concelho de Baião. Arqueologia, 11: 182-183.

Jorge, V.O; Alonso, F. \& Delibrias, G. 1988. Novas datas de carbono 14 para mamoas da serra da Aboboreira. Arqueologia, 18: 95-98.

Medeiros, A.C.; Pilar, L. \& Fernandes, A.P. 1964. Carta Geológica de Portugal na escala de 1/50 000. Noticia explicativa da Folha 13-B - Castelo de Paiva. Lisboa: Serviços Geológicas de Portugal.

Meijide CAmeselle, G. 1995. La necrópole del Bronce Inicial del Agro de Nogueira (Toques, A Coruña). Actas del XXII Congresso Nacional de Arqueologia. (Vigo 2003). Vol. 2.Vigo, 85-88.

Pereira DA Silva, F. 1997. Contextos Funerários da Idade do Bronze nos Planaltos Centrais do Centro-Norte Litoral Português: tradição ou inovação? Actas do II Congresso de Arqueologia Peninsular. Neolitico, Calcolitico y Bronce. Vol. 2. Zamora: Fundación Rey Afonso Henriques, 605-620.

Pereira Da Silva, F. \& Silva, A.M.S.P. 1994. Menires de Alvarenga e da Serra da Freita (Arouca, Aveiro): Breve Notícia. Actas das $5^{a}$ Jornadas Arqueológicas. Vol. 2. Lisboa: Associação dos Arqueólogos Portugueses, 109-123.

SÁ, A.A.; BrIlHa, J.; Rocha, D.; COUTO, H.; RÁBANO, I.; MEDINA, J.; GUTIÉRREZ-MARCO, J.C.; CACHÃO, M. \& VALÉRIO, M. 2008. Geoparque de Arouca. Geologia e Património Geológico. Arouca: Câmara Municipal de Arouca.

SÁ, E., Bettencourt, A.M.S. \& Simões, P.P. 2014.Arquiteturas funerárias, materiais de construção e interação com o espaço na Idade do Bronze da Serra da Freita (Centro -Norte de Portugal). O caso do tumulus de Laceiras do Côvo 3, Vale de Cambra. Estudos do Quaternário, 10: 25-33.

Silva, A.M.S.P. 1994. Proto-história e Romanização no Entre Douro e Vouga Litoral. Elementos para uma avaliação crítica. Porto: Faculdade de Letras da Universidade do Porto (Dissertação de MestradoPolicopiada).

SiLVA, A.M.S.P. (coord.) 2004. Memórias da Terra - Património Arqueológico do Concelho de Arouca. Arouca: Câmara Municipal de Arouca.

VILAÇA, R. 1995. Aspectos do povoamento da Beira Interior (Centro e Sul) nos finais da Idade do Bronze. Vols. 2. Trabalhos de Arqueologia 9. Lisboa: IPPAR. 